$\begin{array}{ll}\text { Research Square } & \text { Preprints are preliminary reports that have not undergone peer review. } \\ \text { They should not be considered conclusive, used to inform clinical practice, } \\ \text { or referenced by the media as validated information. }\end{array}$

\title{
Percutaneous intra-articular injections of ropivacaine, and tranexamic acid and removal of the drainage tube one day after total knee arthroplasty as a component of enhanced recovery after surgery: a randomized control trial
}

\author{
Lijia Pei \\ The First Affiliated Hospital of Bengbu Medical College \\ Xiaoyang Li \\ The First People's Hospital of Chuzhou City \\ Yang Liu \\ The First Affiliated Hospital of Bengbu Medical College \\ Xuyi Wang \\ The First Affiliated Hospital of Bengbu Medical College \\ Hai Ding \\ The First Affiliated Hospital of Medical College \\ Zhiyan Wang \\ The First Affiliated Hospital of Medical College \\ xinshe zhou ( greatzxs@163.com) \\ The First Affiliated Hospital of Bengbu Medical College
}

Research article

Keywords: enhanced recovery after surgery, total knee arthroplasty, tranexamic acid, ropivacaine

Posted Date: February 17th, 2020

DOI: https://doi.org/10.21203/rs.2.23655/v1

License: (c) (1) This work is licensed under a Creative Commons Attribution 4.0 International License. Read Full License 


\section{Abstract}

Background: Intraoperative injections of ropivacaine and tranexamic acid have an increasing role as part of analgesia and haemostasis for enhanced recovery after Total Knee Arthroplasty. However, drug efficiency gradually disappears one day after surgery. Drainage tube placed for too long can cause various complications. This study evaluates whether the postoperative injections of ropivacaine, and tranexamic acid and removal of the drainage tube one day would promote recovery after TKA.

Methods: A total of 80 participants were randomly assigned to two groups. One group was treated with additional intra-articular injections at 08:30 on postoperative day 1 and the removal of drainage tube simultaneously (Trial Group). Another group was dealt with no injection and removal of the drainage tube responding to the amount of drainage fluid (Control Group). The multi-drug solution included $100 \mathrm{mg}$ ropivacaine, and $1 \mathrm{~g}$ tranexamic acid, and $10 \mathrm{~mL}$ saline. The primary outcomes assessed included visual analog scale score, length of hospital stay after surgery, the circumference of the knee, total blood loss volume.

Results: The group that received an additional intra-articular injection of ropivacaine had a significantly lower area under the curve for visual analog scale score than the no injection group at rest $(424 \pm 32$ compared with $515 \pm 39, p=0.003)$. The Trial Group can reduce the length of hospital stay after surgery over the Control Group ( $7.1 \pm 3.1$ days compared with $8.7 \pm 3.2$ days, $p=0.003)$. The group that received an additional intra-articular injection of tranexamic acid have no difference in total blood loss volume \& the circumference of knee joint over the no additional intra-articular injection group ( $910.6 \pm 385.3 \mathrm{~mL}$ compared with $974.8 \pm 408.2 \mathrm{~mL}, \mathrm{p}=0.47 \& 38.9 \pm 5.4 \mathrm{~cm}$ compared with $38.8 \pm 2.4 \mathrm{~cm} \rrbracket p=0.91$ ).

Conclusions: Intra-articular injection of ropivacaine, and tranexamic acid and removal of the drainage tube one day after TKA can further promote recovery after TKA. Keywords: enhanced recovery after surgery, total knee arthroplasty, tranexamic acid, ropivacaine

\section{Background}

As people live longer, an increasing number of patients with end-stage knee joint diseases undergo total knee arthroplasty(TKA). Increasing evidence shows that TKA is a safe and effective therapy that can relieve pain and improve knee function (1). Factors that affect enhanced recovery after surgery (ERAS) include pain, blood loss and drainage tube extraction time.

Multimodal analgesia can reduce the initial pain of TKA. At present, femoral and Sciatic nerve block, epidural analgesia, patient controlled intravenous analgesia, and continuous intra-articular infiltration of analgesics are used in clinical multimodal analgesia. All of the above methods will produce a variety of problems, such as infection, urinary retention, nausea, vomiting, drowsiness, nerve injury, and most importantly prolonged bed rest. (2) Topical intraarticular/peri-articular analgesic injections have been used in clinical multimodal analgesia during surgery (3). According to the drug details of ropivacaine, the half-life period is within 5 hours. The visual analog scale (VAS) score for pain was elevated shaply 24 hours after TKA (4) (5). Rebounding pain one day after surgery remains an important challenge in multimodal analgesia (6). A technique of a percutaneous intra-articular ropivacaine injection one day after TKA was developed, and does not affect the patient's early ambulation activities. The technique is also possible to significantly reduce postoperative pain

Perioperative bleeding remains a severe issue in TKA, causing swelling, anaemia, and elevated blood transfusion rate. (7) Several measures have been used to reduce the bleeding incidence, blood loss volume and blood transfusion rate, including controlled hypertension, tourniquets, intraoperative intravenous/intraarticular tranexamic acid (TXA), and the application of cryotherapy after TKA, using the bandaging technique after TKA (8). TXA is an antifibrinolytic medication. In the operation, TXA can be applied either intravenously or intra-articulary, and has good results. However, the patients are exposed to an uncertain risk of drug intravenously-TXA induced venous thromboembolism (VTE) complications due to a high systemic concentration (9).Compared with intravenous TXA, intra-articular TXA can provide a local maximum concentration of TXA and inhibit local activation of fibrinolysis in the knee, thereby prolonging the postoperative haemostatic effect. Intra-articular injections of TXA are associated with minimal systemic concentration levels, which can increase their safety. Numerous articles have shown valid evidence supporting the effectiveness of intra-articulary-TXA in reducing blood loss in TKA (10) (11). In addition, intra-articular injections of TXA can effectively reduce blood loss while reducing knee joint swelling (12). According to the TXA drug details, $90 \%$ of the metabolite of TXA was excreted 24 hours after intravenous injection.

According to the established convention, the use of a drainage tube after TKA could prevent the formation of haematoceles, relieve swelling, and reduce the incidence of deep infections. Therefore, drainage tubes have been used in most hospitals in China (13) (14). Drainage tubes are also placed in other countries according to the literature (15). Drainage tubes are typically placed after TKA, and the concentration of TXA will gradually decrease or even disappear in the knee joint cavity as blood flows through the drainage tube. ERAS are gradually applied in TKA. Patients demand faster recovery in terms of knee function, and the drainage tube can be removed earlier. The total amount of blood that flowed from the drainage tube within 12 hours accounted for $89.3 \%$ of the entire blood loss volume. Therefore, a strategy with a percutaneous intra-articular TXA injection technique one day after TKA and simultaneous removal of the drainage tube was developed, and promote early ambulation activity.

We conducted a randomized, controlled trial with the aim of investigating the impact of a percutaneous intra-articular ropivacaine, and TXA injection and simultaneous removal of the drainage tube one day following TKA on enhanced recovery after TKA. We hypothesized that a percutaneous intra-articular ropivacaine, and TXA injection and simultaneous removal of the drainage tube one day after TKA would reduce the VAS score at rest and during activity, length of hospital stay after surgery, total blood loss volume (TBLV), volume of blood lost through drainage tube, and total analgesic (non-steroidal antiinflammatory drug) consumption, and improve the range of motion (ROM) of the knee joint.

\section{Methods}




\section{Study design}

We conducted a single-centre, randomized-controlled trial conducted in the Joint Surgery Department ward of the First Affiliated Hospital of Bengbu Medical College. The trial was approved by the ethical committees of the First Affiliated Hospital of Bengbu Medical College. Written informed consent was obtained from all participating patients. A simple random number table generated a random number sequence. Participants were randomly allocated to the Trial or Control Group. This procedure was carried out by a research nurse who did not take part in the outcome assessment.

\section{Study population}

By communicating well with the patients diagnosed with primary osteoarthritis, we enrolled 80 patients underwent unilateral TKA from September 2016 to September 2018. Because the outcomes were short-term estimations and very few complications occurred in the experiment, patient compliance was good. We prespecified the inclusion criteria as patients with an age younger than 80 years, weight below $80 \mathrm{~kg}$ and unilateral knee. The exclusion criteria were as follows: refusal to participate, unable to cooperate, revision TKA, allergy or intolerance to TXA and ropivacaine, major psychological problems, renal insufficiency, hepatic insufficiency, history of previous thromboembolism, history of stroke, and bilateral TKA.

\section{Randomization}

The patients were randomly assigned to two groups, by a computerized randomization list: Trial Group, percutaneous intra-articular injections of ropivacaine, and TXA and simultaneous removal of the drainage tube (0-24 hours after surgery) one day after TKA; Control Group, no intra-articular injections one day after TKA, and the drainage tube was pulled out when the amount of drainage fluid was below $50 \mathrm{~mL} / 24$ hours (2-4 days after surgery).

\section{Perioperative identical medications in both groups}

Preoperative antibiotic prophylaxis for infection was administered intravenously in both groups with first generation cephalosporin antibiotics half an hour before surgery. Intraoperatively we routinely applied periarticular multisite infiltration for perioperative pain management. A total injection volume of $70 \mathrm{~mL}$ of the drug solution included 70 mg ropivacaine (Jia Bo Pharmaceutical Co. Ltd, Qing Yuan city, Guang Dong Province, China) as a local anesthetic, and 0.1 mg epinephrine (Sui Cheng Pharmaceutical Co. Ltd, Xin Zheng city, He Nan Province, China). The drug-containing solution was injected into both side of the posterior joint capsule, quadriceps tendon, medial and lateral capsule, and subcutaneous tissue around the incision just prior to implantation prosthesis. After suturing the deep fascia, a $15 \mathrm{~mL}$ solution containing $2 \mathrm{~g}$ TXA (Wu Zhou Pharmaceutical Co. Ltd, Wu Zhou city, Guang Xi Province, China) [0.5 mg] was injected into the joint cavity before subcutaneous closure. The drainage tube was opened after being clamped for two hours. Except for additional intraarticular injection of TXA and ropivacaine in trial group one day after TKA, the medications administered were the same in both groups. Starting the day after TKA, $40 \mathrm{mg}$ of the non-steroid anti-inflammatory drug parecoxib sodium was given intravenously two times per day. If the patient's pain remained intolerable, we administered 100 mg tramadol (Meng Di Pharmaceutical Co. Ltd, Tong Zhou District, Bei Jing city, China) as rescue therapy. After surgery, every patient received standard thromboembolism prophylaxis based on the guidelines. The patients were given physiotherapy by means of passive and active physiotherapy, and lower-extremity strength training, which were overseen by the professional physiotherapist after surgery in a progressive manner. A continuous passive motion (CPM) machine was applied to improve the range of motion as tolerated, twice a day. For chemical prophylaxis, subcutaneous injection of low-molecular-weight heparin (Hong Ri pharmaceutical Co. Ltd, Tian Jing city, China, 3200 IU, qd) was administered subcutaneously to prevent deep vein thrombosis (DVT) during hospitalization.

\section{Surgical procedure}

At our institution囚all surgical procedures were performed by the corresponding author, who is an experienced arthroplasty surgeon. A pneumatic tourniquet was used around the upper thigh throughout the operation. We designed a standard medial prepatellar skin incision. During the surgical procedure, we expanded the skin incision as needed to fully expose the knee joint. Osteotomy of the femur and tibia were performed with the help of osteotomy instruments. The femoral medullary cavity canal was plugged with a bone block. All patients received posterior stabilized knee prostheses that were fixed with cement and the patella was resurfaced. At the end of the surgical procedure, an intra-articular drainage tube was applied in all patients in our joint surgery ward. Pressure dressing was applied from the ankle to the thigh. An ice pack was placed around the knee joint until 24 hours after surgery.

\section{Interventions}

The additional percutaneous intra-articular multi-drugs injection was administered one day after TKA in the Trial Group, and no injection was provided for the Control Group. An additional intra-articular injection of multi-drug was administered at 08:30 one day after TKA, without considering the end time of TKA. In the Trial Group, Multi-drugs injections included ropivacaine $100 \mathrm{mg}(10 \mathrm{~mL})$, TXA $1 \mathrm{~g}$ and saline $10 \mathrm{~mL}$. We recommended that the patient actively exercise the knee joint to promote blood flow before drainage tube removal in the Trial Group; then we remove the drainage tube. The injection was performed above the patella on either side of the quadriceps tendon using a $20 \mathrm{~mL}$ injector during knee extension (Fig. 1). Povidone iodine and ethanol were applied to disinfect the skin, and a total of $20 \mathrm{~mL}$ drug solution was injected intra-articularly into the knee. We need to make sure that all of the drug solution goes into the joint cavity. In control group, the patients did not receive additional intra-articular injection. Drainage tube removed according to the amount of drainage fluid below 50 $\mathrm{mL} / 24$ hours. Removal of the drainage tube may take 2 to 4 days after surgery.

\section{Outcome measurement}

A research assistant who was not involved in the research collected data. The research assistants were blinded to whether an intra-articular ropivacaine, and TXA injection was used one day after surgery. 
The primary outcome variables were length of hospital stay after surgery, and an assessment of the VAS score, which scaled from 0 mm (representing no pain) to $100 \mathrm{~mm}$ (representing extreme pain), was performed at rest and during movement. Postoperative pain was assessed via the VAS 1, 2, 3, 4 and 5 days after surgery $(7: 00,12: 00$, and 20:00). The most intense pain that the patients underwent throughout a physical recovery treatment was identified as the VAS score of the activity.

The secondary outcomes of this study were the total analgesic (non-steroidal anti-inflammatory drug) consumption, ROM of the knee joint, TBLV, blood transfusion rate, amount of blood lost through the drainage tube, the circumference of the knee joint $(10 \mathrm{~cm}$ above the superior border of the patella and patella centre), wound related complications such as infection, and symptomatic DVT within 30 days of surgery.

We calculated the Total blood loss in accordance with the following formula (16). Total blood loss = PBV ' $\left(\right.$ Hct $_{\text {pre }}-$ Hct $\left._{\text {post }}\right) /$ Hct $_{\text {ave, }}$, where PBV, Hct pre, $\mathrm{Hct}_{\text {post }}$ and $\mathrm{Hct}_{\text {ave }}$ stand for Patient's Blood Volume, Initial Preoperative Haematocrit, Haematocrit level on the morning of the fourth postoperative day \& Average of

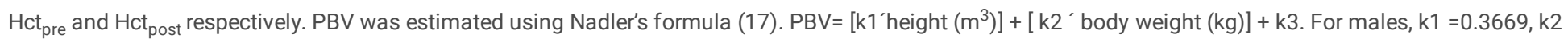
$=0.03219$, and $\mathrm{k} 3=0.1833$, and for females, it was $\mathrm{k} 1=0.6041, \mathrm{k} 2=0.03308$, and $\mathrm{k} 3=0.1833$. Because a tourniquet was used throughout the operation, the blood loss was negligible during operation.

\section{Sample size calculation}

Forty participants per group would be required for this trial to illustrate a statistically significant difference with a 10 point reduction in the VAS pain scale score, a $200 \mathrm{~mL}$ decrease in blood loss, a 5\% significance level, $80 \%$ power and two-sided analysis. (18)

\section{Statistical analyses}

GraphPad Prism 8 software was used for statistical analysis. Missing values were replaced by the average values of the same group at the same time point. We performed all data analyses according to the principle of intention-to-treat. Student's t-test was used to compare continuous variables. The chi-square test was used to compare categorical variables. Continuous variables are represented as the mean \pm SD. Statistical significance was defined as $p<0.05$.

\section{Results}

\section{Participants}

A total of 132 patients were enrolled in our study. Fifty-two patients were excluded secondarily, the remaining 80 patients were allocated to the trial group (intra-articular injection) and the control group (no intra-articular injection) at random. Figure 2 describes the trial process. Table 1 detailed the clinical data of the patients.

Table 1

The clinical data of the patients

\begin{tabular}{|c|c|c|c|}
\hline Index & Additional intra-articular injection (40 patients) & No additional intra-articular injection(40patients) & P-value \\
\hline Age, years & $65.5 \pm 8.1$ & $66.7 \pm 8.2$ & $0.42^{\mathrm{a}}$ \\
\hline Sex (Female/Male) & $31 / 9$ & $33 / 7$ & $0.83^{b}$ \\
\hline Height, mm & $157.2 \pm 10.5$ & $156.3 \pm 9.2$ & $0.65^{\mathrm{a}}$ \\
\hline Weight, kg & $65.2 \pm 11.5$ & $64.5 \pm 12.4$ & $0.79^{a}$ \\
\hline Body mass index, $\mathrm{kg} / \mathrm{m}^{2}$ & $26.4 \pm 3.8$ & $26.8 \pm 2.9$ & $0.84^{a}$ \\
\hline Preoperative VAS at rest, $\mathrm{mm}$ & $33.5 \pm 12.2$ & $35.1 \pm 13.5$ & $0.88^{a}$ \\
\hline $\begin{array}{l}\text { Preoperative VAS during activity, } \mathrm{mm} \\
\text { Preoperative flexion angle, degree } \\
\text { Preoperative extension angle, degree } \\
\text { Duration of operation, min }\end{array}$ & $\begin{array}{l}45.2 \pm 15.4 \\
126.3 \pm 21.2 \\
-9.2 \pm 9.8 \\
88.9 \pm 9.5\end{array}$ & $\begin{array}{l}47.5 \pm 16.4 \\
128.5 \pm 20.2 \\
-9.8 \pm 9.2 \\
86.5 \pm 10.2\end{array}$ & $\begin{array}{l}0.84^{\mathrm{a}} \\
0.59^{\mathrm{a}} \\
0.52^{\mathrm{a}} \\
0.49^{\mathrm{a}}\end{array}$ \\
\hline
\end{tabular}

\section{Primary Outcome}

Figure 3 The mean and standard deviation of the visual analogue scale scores at different time points after total knee arthroplasty at rest. The mean area under the curve was 424 in the additional intra-articular injection group compared with 515 in the no additional intra-articular injection group ( $p=0.003$ ). The mean VAS scores at each point are in a Table 2. 
Table 2

VAS scores of postoperative pain at rest

\begin{tabular}{|c|c|c|c|}
\hline Measurement time & Additional intra-articular injection (40 patients) & No additional intra-articular injection (40 patients) & P Value ${ }^{a}$ \\
\hline $\begin{array}{l}\text { Postoperative day } 0,20: 00 \\
\text { Postoperative day 1, 07:00 } \\
\text { Postoperative day 1, 12:00 } \\
\text { Postoperative day } 1,20: 00\end{array}$ & $\begin{array}{l}22.5 \pm 8.9 \\
31 \pm 8.7 \\
19.7 \pm 8.9 \\
21.2 \pm 11.3\end{array}$ & $\begin{array}{l}23.0 \pm 9.7 \\
30.5 \pm 9.9 \\
35.5 \pm 14.8 \\
41.5 \pm 18.3\end{array}$ & $\begin{array}{l}0.99 \\
0.61 \\
0.001 \\
0.001\end{array}$ \\
\hline $\begin{array}{l}\text { Postoperative day } 2,07: 00 \\
\text { Postoperative day } 2,12: 00 \\
\text { Postoperative day } 2,20: 00 \\
\text { Postoperative day } 3,07: 00 \\
\text { Postoperative day } 3,12: 00 \\
\text { Postoperative day } 3,20: 00 \\
\text { Postoperative day } 4,07: 00 \\
\text { Postoperative day } 4,12: 00 \\
\text { Postoperative day } 4,20: 00 \\
\text { Postoperative day } 5,07: 00 \\
\text { Postoperative day } 5,12: 00 \\
\text { Postoperative day } 5,20: 00\end{array}$ & $\begin{array}{l}28.2 \pm 13.3 \\
28.8 \pm 14.5 \\
30.8 \pm 14.7 \\
34.5 \pm 15.2 \\
30.0 \pm 12.4 \\
33.3 \pm 12.8 \\
30.3 \pm 13.1 \\
27.0 \pm 13.2 \\
29.3 \pm 10.4 \\
30.0 \pm 10.6 \\
26.5 \pm 9.8 \\
25.3 \pm 6.8\end{array}$ & $\begin{array}{l}39.8 \pm 16.9 \\
36.8 \pm 16 \\
41.5 \pm 17.0 \\
38.5 \pm 16.3 \\
33.3 \pm 13.5 \\
38.3 \pm 14.3 \\
34.0 \pm 14.8 \\
29.5 \pm 12.2 \\
33.3 \pm 15.9 \\
32.0 \pm 12.0 \\
27.3 \pm 8.5 \\
25.6 \pm 9.0\end{array}$ & $\begin{array}{l}0.002 \\
0.01 \\
0.001 \\
0.25 \\
0.17 \\
0.29 \\
0.25 \\
0.26 \\
0.50 \\
0.53 \\
0.48 \\
0.69\end{array}$ \\
\hline
\end{tabular}

\section{Secondary Outcomes}

Table 3 shows that there was no significant difference involving VAS score in two groups during activity $(P>0.05)$.

Table 3

VAS scores of postoperative during activity

\begin{tabular}{|lllc|}
\hline Measurement time & Additional intra-articular injection (40 patients) & No additional intra-articular injection (40 patients) & P Value ${ }^{\text {a }}$ \\
\hline Postoperative day 1 & $42.5 \pm 14.3$ & $47.2 \pm 19.8$ & 0.23 \\
\hline Postoperative day 2 & $48.2 \pm 16.6$ & $52.3 \pm 16.5$ & 0.27 \\
\hline Postoperative day 3 & $45.5 \pm 12.5$ & $50.4 \pm 15.4$ & 0.14 \\
\hline Postoperative day 4 & $42.2 \pm 14.5$ & $46.3 \pm 15.6$ & 0.23 \\
\hline Postoperative day 5 & $35.4 \pm 12.6$ & $39.5 \pm 13.2$ & 0.16 \\
\hline VAS scores are expressed as the mean \pm standard deviation. P values were determined with the Student's t-test.
\end{tabular}

Table 4 illustrates that the mean number of parecoxib sodium doses applied were similar between the two groups. The group that received an additional intraarticular injection and removal of the drainage tube one day after TKA had a statistically significant advantage in terms of reducing the length of hospital stay after surgery over the group that did not received an additional intra-articular injection ( $7.1 \pm 3.1$ days compared with $8.7 \pm 3.2$ days, $p=0.003)$. The group that received an intra-articular injection and removal of the drainage tube one day after TKA did not have significant difference in terms of the circumference of the knee joint over the no additional intra-articular injection group $(p>0.05)$.No incision or surgical site infections were recorded in either group. The skin around the local injection sites healed well. No DVT events occurred in either group. One case of superficial vein thrombosis occurred in the intra-articular injection group. The patient did not show DVT-related clinical symptoms. The patient treated according to the usual thromboembolism prophylaxis protocol and was regularly discharged. One case of fat liquefaction occurred in the no intra-articular injection group, and this patient was cured after continual dressing changes. 
Table 4

Clinical parameters after TKA.

\begin{tabular}{|c|c|c|c|}
\hline Index & $\begin{array}{l}\text { Additional intra-articular injection } \\
\text { ( } 40 \text { patients) }\end{array}$ & $\begin{array}{l}\text { No additional intra-articular injection } \\
\text { ( } 40 \text { patients) }\end{array}$ & $\begin{array}{l}\mathrm{P} \\
\text { Value }\end{array}$ \\
\hline $\begin{array}{l}\text { Amount of analgesic drugs consumed during hospitalization, } \\
\text { count } \\
\text { Length of hospital stay after surgery, days } \\
\text { Circumference } 10 \mathrm{~cm} \text { above the superior border of the patella } \\
\text { (Preoperatively) }, \mathrm{cm} \\
\text { Circumference } 10 \mathrm{~cm} \text { above the superior border of the patella } \\
\text { (postoperative day } 4 \text { ),cm } \\
\text { Circumference of patella centre(Preoperatively),cm } \\
\text { Circumference of patella centre (postoperative day } 4 \text { ),cm } \\
\text { Infection }\end{array}$ & $\begin{array}{l}9.15 \pm 7.4 \\
7.1 \pm 3.1 \\
40.9 \pm 4.0 \\
41.3 \pm 4.7 \\
37.5 \pm 2.4 \\
38.9 \pm 5.4 \\
0\end{array}$ & $\begin{array}{l}8.8 \pm 6.4 \\
8.7 \pm 3.2 \\
41.3 \pm 4.4 \\
41.9 \pm 4.5 \\
36.9 \pm 3.4 \\
38.8 \pm 2.4 \\
0\end{array}$ & $\begin{array}{l}0.88 \\
a \\
0.03 \\
a \\
0.67 \\
a \\
0.56 \\
a \\
0.37 \\
a \\
0.91 \\
a \\
1.00 \\
b\end{array}$ \\
\hline $\begin{array}{l}\text { Deep vein thrombosis(DVT) } \\
\text { Superficial vein thrombosis } \\
\text { Fat liquefaction }\end{array}$ & $\begin{array}{l}0 \\
1 \\
0\end{array}$ & $\begin{array}{l}0 \\
0 \\
1\end{array}$ & $\begin{array}{l}1.00 \\
b \\
0.31^{b} \\
0.31^{b}\end{array}$ \\
\hline
\end{tabular}

Table 5 demonstrates that the intra-articular injection group did not have significantly better range of knee motion than the no intra-articular injection group.

Table 5

Range of motion following TKA

\begin{tabular}{|c|c|c|c|}
\hline Measurement time & Additional intra-articular injection (40 patients) & No additional intra-articular injection (40 patients) & P Value \\
\hline $\begin{array}{l}\text { Flexion angle } \\
\text { Postoperative day } 112: 00\end{array}$ & $72.5 \pm 14.2$ & $70.7 \pm 13.5$ & 0.56 \\
\hline Postoperative day 2 12:00 & $79.6 \pm 11.3$ & $81.1 \pm 9.2$ & 0.59 \\
\hline Postoperative day 3 12:00 & $85.4 \pm 10.2$ & $84.8 \pm 11.6$ & 0.82 \\
\hline Postoperative day 4 12:00 & $88.5 \pm 10.6$ & $89.8 \pm 12.2$ & 0.63 \\
\hline $\begin{array}{l}\text { Postoperative day } 5 \text { 12:00 } \\
\text { Extension angle } \\
\text { Postoperative day } 1 \text { 12:00 } \\
\text { Postoperative day } 2 \text { 12:00 } \\
\text { Postoperative day } 3 \text { 12:00 } \\
\text { Postoperative day } 4 \text { 12:00 } \\
\text { Postoperative day } 5 \text { 12:00 }\end{array}$ & $\begin{array}{l}91.8 \pm 11.7 \\
-9.2 \pm 2.2 \\
-7.3 \pm 3.4 \\
-7.2 \pm 2.5 \\
-6.5 \pm 3.3 \\
-6.3 \pm 3.2\end{array}$ & $\begin{array}{l}90.3 \pm 12.3 \\
-8.5 \pm 2.3 \\
-7.8 \pm 2.2 \\
-7.6 \pm 3.3 \\
-7.2 \pm 4.5 \\
-6.2 \pm 4.5\end{array}$ & $\begin{array}{l}0.60 \\
0.75 \\
0.82 \\
0.85 \\
0.43 \\
0.91\end{array}$ \\
\hline
\end{tabular}

Table 6 illustrates that the group that received an intra-articular injection and removal of the drainage tube one day after TKA had a statistically significant advantage in terms of reducing the total amount of blood lost through the drainage tube over the no intra-articular injection group. An intra-articular injection and removal of the drainage tube one day after TKA did not have a statistically significant advantage in term of TBLV over the no intra-articular injection group. Three patients received allogeneic blood transfusions, including two patients (5\%) in intra-articular injection group and one patient (2.5\%) in no intraarticular injection group. The group that received an intra-articular injection and removal of the drainage tube one day after TKA had a statistically significant advantage in terms of the days of drainage tube removal over the no intra-articular injection group $(1.0 \pm 0$ days compared with $1.8 \pm 0.7$ days, $p=0.000)$.

Table 6

Comparison of TBLV, blood lost through the drainage tube, drainage tube removal (mean \pm SD)

\begin{tabular}{|c|c|c|c|}
\hline Index & $\begin{array}{l}\text { Additional intra-articular injection ( } 40 \\
\text { patients) }\end{array}$ & $\begin{array}{l}\text { No additional intra-articular injection (40 } \\
\text { patients) }\end{array}$ & P Value \\
\hline $\begin{array}{l}\text { Blood lost through the drainage tube, } \\
\mathrm{mL} \\
\text { Total blood loss volume, } \mathrm{mL} \\
\text { Blood transfusion } \\
\text { Days of drainage tube removal, days }\end{array}$ & $\begin{array}{l}145.6 \pm 47.4 \\
910.6 \pm 385.3 \\
2 \\
1.0 \pm 0\end{array}$ & $\begin{array}{l}205.7 \pm 60.3 \\
974.8 \pm 408.2 \\
1 \\
1.8 \pm 0.7\end{array}$ & $\begin{array}{l}0.47^{\mathrm{a}} \\
0.000^{\mathrm{a}} \\
0.56^{\mathrm{b}} \\
0.000^{\mathrm{a}}\end{array}$ \\
\hline
\end{tabular}




\section{Discussion}

ERAS programmes are a peri-operative multimodal optimization schemes that aim to improve peri-operative outcomes, including reduced length of hospital stay after surgery, shortened postoperative functional convalescence, and reduced complications and medical costs.

The purpose of the trial is to assess whether the postoperative injections of ropivacaine, and TXA and removal of the drainage tube one day would promote recovery after TKA.To our knowledge, no research has been published on this aspect.

The study indicated that mean VAS scores showed that the degree of pain at rest was acceptable to the patients in trial group. The trial group had significantly lower cumulative postoperative pain VAS scores at rest than the control group during the five-day postoperative period. In addition, the VAS pain score was lower in the intra-articular injection group than in the no injection group during activity, but the difference was not statistically significant. Patients receiving intraoperative injections of multiple drug for analgesia generally felt the rebounding pain one day after TKA (19) (20). The difference in the VAS pain scores between groups was most pronounced on the first day after surgery. We believe that the difference is meaningful to relieve patients' pain on postoperative day 1.

To the best of our knowledge, postoperative continuous intra-articular infusions of anaesthetic through catheters have been applied for pain management after TKA (21). With an increasing number of orthopaedist accepting the concept of ERAS, patients with catheters that supply continuous intra-articular infusions of anaesthetics experience delays in getting out of bed; therefore, this method is not conducive to ERAS. Catheters can cause complications related to wound healing, including deep infections (22). The unique advantage of our technique was that no infusion catheter needed to be placed and patients can be early ambulation activities in this study.

A recent study showed that patients undergoing TKA had the highest dose of opioid medication among those undergoing the selective orthopaedic surgery, and we must find effective ways to treat patients with non-opioid analgesia (23). We believe that our additional percutaneous intra-articular injection ropivacaine one day after TKA is another option to reduce pain after TKA.

TXA is a powerful antifibrinolytic drug and its effective role in reducing blood loss has been reported in many studies (24). TXA administration can be accomplished through intravenous, intramuscular, intra-articular, and oral routes (25). A number of studies have shown similar effects between the intraarticular application and intravenous application TXA (26). TXA is an effective antifibrinolytic agent; therefore, some are worried about an elevated the incidence of thrombosis due to systemic application, although numerous previous studies have reported no risk of thrombosis (27). The intra-articular application of TXA has many advantages. First, TXA inhibits local fibrinolytic activity by acting directly on the bleeding site. Second, intra-articular administration of TXA leads to very low systemic absorption and does not form venous thrombosis. Third, high concentrations of TXA in the joint can lead to greater haemostasis effect and shorter vascular occlusion. Fourth, intra-articular administration of TXA can reduce knee swelling after TKA. In our department of orthopaedic surgery, we routinely use intra-articular injections of TXA to reduce the total blood loss volume in TKA.

Naturally, combined with the use of intraoperative and postoperative intra-articular injection of TXA may have enhanced effects on haemostasis. To our knowledge, there is no research describing whether this combination has clinical usefulness.

Our major finding is that if the knee joint cavity is injected with TXA during surgery, a percutaneous intra-articular injection TXA one day after TKA will not reduce the blood loss and transfusion rate of the patients. The reason for this result is that the total amount of blood flowing out of the drainage tube within 12 hours accounted for most of the total blood loss. Shao yun Zhang et al removed the drainage tube 18 hours after surgery, and total blood loss volume that flowed from the drainage tube within 12 hours accounted for $89.3 \%$ of the entire blood loss (28). C. Legnani et al showed that preoperative and postoperative intravenous TXA did not significant decrease the volume of blood loss compared to preoperative intravenous dose of TXA. This result is the same as our results. However, contrary to our observation, C. Legnani et al found that preoperative and postoperative intravenous TXA are more effective than a single preoperative intravenous TXA in terms of reducing transfusion requirements (29). Iwai T et al showed that preoperative and postoperative intravenous TXA led to less blood loss and lower transfusion requirements than a single preoperative intravenous TXA (30). Similar to most authors, we also found that the use of TXA was safe. No incidences of DVT were reported in either group. The percutaneous intra-articular injection did not lead to any wound-related complications.

There is no consensus on whether a drainage tube should be used and when it should be removed after TKA. First, surgeons are accustomed to using drains to avoid the formation of a haematoma and deep infections. Surgeons think that the use of a drainage tube can reduce swelling and the associated discomfort. However, surgeons against the application of drainage tubes consider that postoperative drainage tubes can increase the amount of blood loss and transfusion rate (31). In addition, with the prolonged use of a drainage tube, the incidence of superficial and deep infections is likely to increase (32). C. N. A. Esler et al showed that the presence of drainage tubes hampers ambulation and complicates care. In our study, there was a statistically important difference the total amount of blood loss through the drainage tube over between patients who had their drainage tubes removed on the first day after surgery and those who had drainage tubes removed from the second to fourth day after surgery. We did not find swelling of the knee or superficial and deep infections in patients who had their drainage tube removed one day after TKA. According to the experimental results, we believe that drainage tubes can be removed on the first day after surgery to avoid swelling in the knee joint, reduce the total drainage volume, prevent the formation of haematoma and avoid the risk of retrograde infection.

First, the limitation of trial is that there were three influencing factors. Because too many factors affect ERAS, further research is needed to confirm the role of individual factors. Second, none of the treatment team members or patients was blinded to trial. Non-blinded designs lead to overestimation in randomized controlled trials. Third, a percutaneous intra-articular multi-drug injections and removal of the drainage tube were routinely performed at 08:30 one day after surgery. Due to different time points at the end of surgery, there was no standardized time from TKA completion to injection. 
The strength of our study is that it is the first study to describe the effectiveness of a double injection of ropivacaine and TXA for ERAS. Second, we believe that using AUC to analyse the resulting outcomes may be an advantage of this study, because AUCs can avoid serious problems caused by using comparison values at each time point.

\section{Conclusions}

By analysing the factors above, a percutaneous intra-articular injection of ropivacaine can significantly reduce postoperative VAS scores at rest after TKA. A percutaneous intra-articular injection of TXA and removal of the drainage Tube one day after TKA did not reduce the total blood loss volume. Removal of the wound drainage tube one day after TKA could prevent haematoceles, reduce the risk of infection,reduce patient activity barriers and facilitate care; additionally, this method prevent the incidence of swelling. A percutaneous intra-articular injection of ropivacaine, and TXA and removal of the drainage tube one day after TKA shortened the length of hospital stay after surgery. A percutaneous intra-articular injection of ropivacaine, and TXA and removal of drainage tube one day after TKA can further promote recovery after TKA and can be used as a component of ERAS.

\section{Abbreviations}

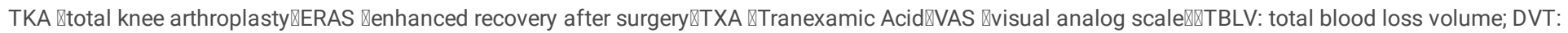
deep vein thrombosis; ROM: Range of motion

\section{Declarations}

\section{Acknowledgements}

Not applicable

\section{Authors' contributions}

All authors read and approved the final manuscript

\section{Funding}

The study was financially supported by the Natural science foundation of bengbu medical College (BYKY1782 and BYKY2019030ZD) and Bengbu municipal science and technology innovation guidance project (2018)

\section{Availability of data and materials}

All relevant raw data generated or analyzed during this study are included in the main manuscript

, which are freely available to any scientist wishing to use them.

\section{Ethics approval and consent to participate}

This study protocol was approved by the Ethics Committee on Human Research of the first affiliated hospital of Bengbu Medical College. All patients received a thorough explanation of this study and informed consent was obtained from all patients.

\section{Consent for publication}

Consent for publication was obtained from all patients, who understood and agreed this study.

\section{Competing interests}

The authors declare that they have no competing interests.

\section{References}

1. Wyles CC, Tibbo ME, Yuan BJ, Trousdale RT, Berry DJ, Abdel MP. Long-Term Results of Total Knee Arthroplasty with Contemporary Distal Femoral Replacement. J Bone Joint Surg Am. 2020; 102(1):45-51

2. Ganapathy S. Wound/intra-articular infiltration or peripheral nerve blocks for orthopedic joint surgery: efficacy and safety issues. Curr Opin Anaesthesiol. 2012;25(5):615-620.

3. Ali A, Sundberg M, Hansson U, Malmvik J, Flivik G. Doubtful effect of continuous intraarticular analgesia after total knee arthroplasty: a randomized double-blind study of 200 patients. Acta Orthop. 2015; 86(3):373-7

4. Tsukada S, Wakui M, Hoshino A. Postoperative epidural analgesia compared with intraoperative periarticular injection for pain control following total knee arthroplasty under spinal anesthesia: a randomized controlled trial. J Bone Joint Surg Am. 2014; 96(17):1433-8.

5. S Tsukada, M Wakui, A Hoshino. The impact of including corticosteroid in a periarticular injection for pain control after total knee arthroplasty: a doubleblind randomized controlled trial. Bone Joint J. 2016; 98(2):194-200. 
6. Murata-Ooiwa M, Tsukada S, Wakui M. Intravenous acetaminophen in multimodal pain management for patients undergoing total knee arthroplasty: a randomized, double-blind, placebo-controlled trial. J Arthroplast. 2017;32(10):3024 -8.

7. Seol YJ, Seon JK, Lee SH, Jin C ,Prakash J,Park YJ, Song EK. Effect of tranexamic acid on blood loss and blood transfusion reduction after total knee arthroplasty. Knee Surg Relat Res. 2016;28(3):188-93.

8. Themistoklis T, Theodosia V, Konstantinos K, Georgios DI. Perioperative blood management strategies for patients undergoing total knee replacement: where do we stand now? World J Orthop . 2017; 8(6):441-454.

9. Ker K, Edwards P, Perel P, Shakur H, Roberts I. Effect of tranexamic acid on surgical bleeding: systematic review and cumulative meta-analysis. BMJ 2012; 344

10. Goyal N, Chen DB, Harris IA, Rowden NJ, Kirsh G, MacDessi SJ. Intravenous vs intra-articular tranexamic acid in total knee arthroplasty: a randomized, double-blind trial. J Arthroplast. 2017;32(1):28-32.

11. Sun X, Dong Q, Zhang YG. Intravenous versus topical tranexamic acid in primary total hip replacement: a systemic review and meta-analysis. Int J Surg 2016;32:10-8.

12. Ishida K, Tsumura N, Kitagawa A, Hamamura S, Fukuda K, Dogaki Y, Kubo S, Matsumoto T, Matsushita T, Chin T, Iguchi T, Kurosaka M, Kuroda R. Intraarticular injection of tranexamic acid reduces not only blood loss but also knee joint swelling after total knee arthroplasty. Int Orthop. 2011 Nov; 35(11):1639-45.

13. Shi M, Zhang J, Zhang Y, Yan S, Wu H. Effect of a 12-hour natural drainage technique on decreasing blood loss after total knee arthroplasty: a casecontrol study. Ther Clin Risk Manag.2018;14:1169-1174

14. Liu XH, Fu PL, Wang SY, Yang YJ, Lu GD. The effect of drainage tube on bleeding and prognosis after total knee arthroplasty: a prospective cohort study. J Orthop Surg Res.2014;9: 27

15. Lee SY, Chong S, Balasubramanian D, Na YG, Kim TK. What is the Ideal Route of Administration of Tranexamic Acid in TKA? A Randomized Controlled Trial. Clin Orthop Relat Res. 2017;475(8):1987-1996.

16. Gross JB. Estimating allowable blood loss: corrected for dilution. Anesthesiology. 1983; 58(3):277-80

17. Duan Wang, Hui Zhu, Wei-Kun Meng, Hao-Yang Wang, Ze-Yu Luo, Fu-Xing Pei, Qi Li1 and Zong-Ke Zho. Comparison of oral versus intra-articular tranexamic acid in enhanced-recovery primary total knee arthroplasty without tourniquet application: a randomized controlled trial. BMC Musculoskelet Disord. 2018; 19(1):85

18. Murata-Ooiwa M, Tsukada S, Wakui M. Intravenous acetaminophen in multimodal pain management for patients undergoing total knee arthroplasty: a randomized, double-blind, placebo-controlled trial. J Arthroplast. 2017; 32(10):3024 -3028.

19. Tsukada S, Wakui M, Hoshino A. The impact of including corticosteroid in a periarticular injection for pain control after total knee arthroplasty: a doubleblind randomized controlled trial. Bone Joint J. 2016;98-B(2):194-200

20. Stathellis A, Fitz W, Schnurr C, Koeck FX, Gebauer M, Huth J, Bauer G, Beckmann J.Periarticular injections with continuous perfusion of local anaesthetics provide betterpain relief and better function compared to femoral and sciatic bloc a randomized clinical trial. Knee Surg Sports Traumatol Arthrosc. 2017; 25(9):2702-2707.

21. Reinhardt KR, Duggal S, Umunna BP, Reinhardt GA, Nam D, Alexiades M, Cornell CN. Intraarticular analgesia versus epidural plus femoral ferve block after TKA: a randomized, double-blind trial. Clin Orthop Relat Res.2014;472(5):1400-1408.

22. Ali A, Sundberg M, Hansson U, Malmvik J, Flivik G. Doubtful effect of continuous intraarticular analgesia after total knee arthroplasty: a randomized double-blind study of 200 patients. Acta Orthop.2015;86(3):373-7.

23. Sabatino MJ, Kunkel ST, Ramkumar DB, Keeney BJ, Jevsevar DS. Excess opioid medication and variation in prescribing patterns following common orthopaedic procedures. J Bone Joint Surg Am.2018; 100(3):180-188.

24. George J1, Eachempati KK2, Subramanyam KN3, Gurava Reddy AV4. The comparative efficacy and safety of topical and intravenous tranexamic acid for reducing perioperative blood loss in Total knee arthroplasty- a randomized controlled non-inferiority trial. Knee. 2018; 25(1):185-191.

25. Ye W, Liu Y, Liu WF, Li XL, Fei Y, Gao X. Comparison of efficacy and safety between oral and intravenous administration of tranexamic acid for primary total knee/hip replacement: a meta-analysis of randomized controlled trial. J Orthop Surg Res. 2020; 15(1):21

26. Lee SY, Chong S, Balasubramanian D, Na YG, Kim TK. What is the Ideal route of Administration of tranexamic Acid in TKA? A randomized controlled trial. Clin Orthop Relat Res. 2017 Aug;475(8):1987-1996.

27. Arslan A, Görmeli G. Using intra-articular tranexamic acid in total knee replacement surgery with and without bleeding control: a prospective randomized double blind study. Eur Rev Med Pharmacol Sci. 2018; 22(18):6127-6132.

28. Zhang S, Xu B, Huang Q, Yao H, Xie J, Pei F. Early Removal of Drainage Tube after Fast-Track Primary Total Knee Arthroplasty. J Knee Surg. 2017; 30(6):571-576.

29. Legnani C, Oriani G, Parente F, Ventura A. Reducing transfusion requirements following total knee arthroplasty: effectiveness of a double infusion of tranexamic acid. Eur Rev Med Pharmacol Sci.2019; 23(5):2253-2256.

30. Iwai T, Tsuji S, Tomita T, Sugamoto K, Hideki Y, Hamada M. Repeat-dose intravenous tranexamic acid further decreases blood loss in total knee arthroplasty. Int Orthop.2013 Mar; 37(3):441-5.

31. Demirkale I, Tecimel O, Sesen H, Kilicarslan K, Altay M, Dogan M. Non-drainage decreases blood transfusion need and infection rate in bilateral total knee arthroplasty. J Arthroplasty 2014; 29(5): 993-997

32. Minnema B, Vearncombe M, Augustin A, Gollish J, Simor AE. Risk factors for surgical-site infection following primary total knee arthroplasty. Infect Control Hosp Epidemiol 2004; 25(6):477-480.

Page $9 / 11$ 


\section{Figures}

\section{原}

Figure 1

Pictures showing the method of intra-articular injection one the day after TKA .Picture A shows removal of the drainage Tube one the day after TKA. Picture B the rectangular box marks the reserved Intraoperatively suture. Picture $C$ the rectangular box marks the suture knot preventing the retrograde infection and the leakage of the drug solution. Picture D shows the injection point was located at the upper position of patella on either side of the quadriceps tendon using a syringe.

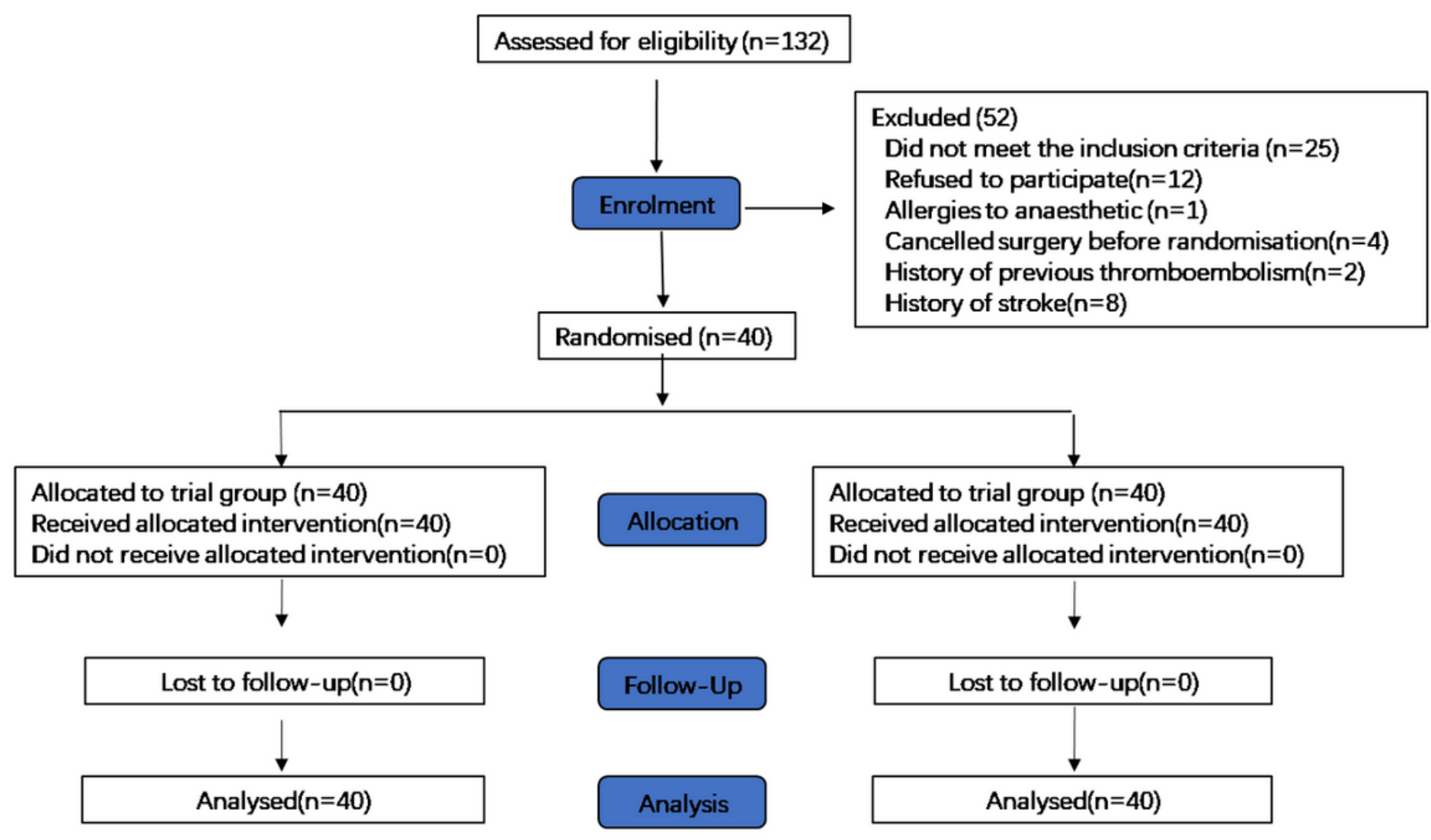

Figure 2

Diagram showing the subject screening and enrollment process 


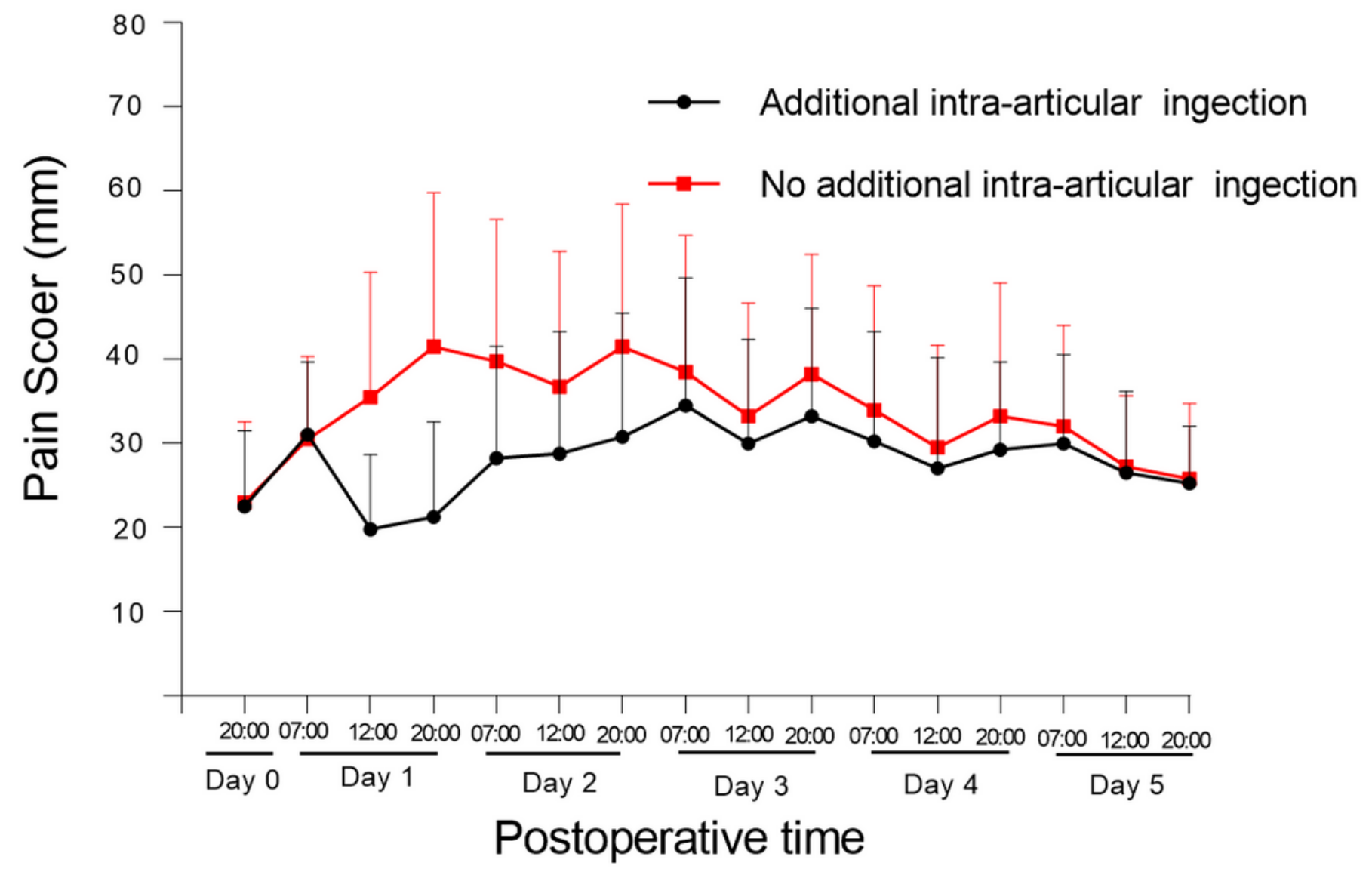

Figure 3

The mean and standard deviation of the visual analogue scale scores at different time points after total knee arthroplasty at rest. The mean area under the curve was 424 in the additional intra-articular injection group compared with 515 in the no additional intra-articular injection group ( $p=0.003$ ). The mean VAS scores at each point are in a table 2 . 